\title{
AVALIAÇÃO DA QUALIDADE DE LEITE CRU ARMAZENADO EM TANQUES DE REFRIGERAÇÃO NO MUNICÍPIO DE ALEGRE, ESPÍRITO SANTO
}

Francisca Carvalho Nascimento $\mathrm{Neta}^{1 *}$, Mateus da Silva Junqueira ${ }^{2}$, Joel Camilo Souza Carneiro ${ }^{2}$, Maria da Penha Piccolo Ramos², Cláudia Lúcia de Oliveira Pinto ${ }^{3}$, Denes Kaic Alves Rosário²

\begin{abstract}
RESUMO - Objetivou-se avaliar a qualidade microbiológica por meio da detecção de bactérias deteriorantes e patogênicas além da detecção de resíduos de antibióticos em leite cru refrigerado produzido em propriedades familiares do município de Alegre, ES. As amostras foram coletadas em quatro tanques de refrigeração coletivos. Realizou-se contagens de bactérias mesófilas e psicrotróficas mediante contagem em Ágar padrão seguido de incubação e contagem. Para a determinação de Staphylococcus spp.; de coliformes totais e E.coli utilizouse kit rápido. Para detecção de antibióticos da classe â-lactâmicos utilizou-se o kit BetaStar@, conforme metodologia descrita pelo fabricante. Verificou-se contagens médias de $1,4 \times 10^{6} \mathrm{UFC} \cdot \mathrm{mL}^{-1}$ para bactérias mesófilas (BM);

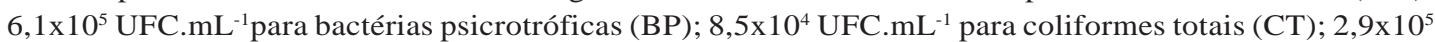

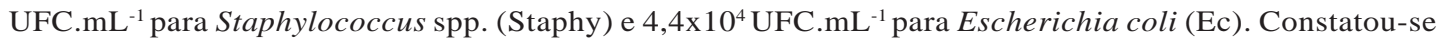
baixa qualidade microbiológica do leite cru refrigerado produzido na região devido ao alto grau de contaminação no produto e não foram detectados resíduos de antibióticos nas amostras. São necessários esforços por parte de todos os envolvidos na cadeia produtiva para que possam se adequar às condições de produção de forma a garantir a inocuidade e qualidade do leite e derivados, além de contribuir para a saúde dos consumidores e a sustentabilidade do setor na região.
\end{abstract}

Palavras-chave: antibiótico, bactérias psicrotróficas higiene, padrões microbiológicos.

\section{QUALITY ASSESSMENT OF MILK RAW STORED IN COOLING TANKS IN ALEGRE CITY, ESPÍRITO SANTO}

\begin{abstract}
This study aimed to evaluate the microbiological quality through the detection of spoilage and pathogenic bacteria as well as of antibiotic residues in refrigerated raw milk produced in family properties in Alegre, ES, Brazil. Samples were withdrawn from four shared cooling tanks. Mesophilic and psychrotrophic bacteria were counted on standard agar after incubation. A rapid kit was used to determine the counts of Staphylococcus spp., total coliforms, and E.coli. The BetaStar ${ }^{\circledR}$ kit was used in order to detect â-lactam antibiotics, in accordance with the methodology proposed by the manufacturer. We obtained the following average counts: mesophilic bacteria (BM), $1.4 \times 10^{6} \mathrm{CFU} . \mathrm{mL}^{-1}$; psychrotrophic bacteria (PB), $6.1 \times 10^{5} \mathrm{CFU} . \mathrm{mL}^{-1}$; total coliforms

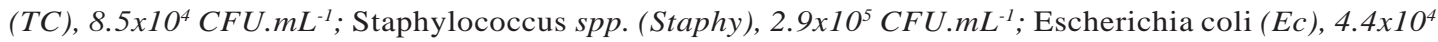
CFU. $m L^{-1}$. The poor microbiological quality observed in the refrigerated raw milk produced in the studied region was attributed to the high degree of contamination. No antibiotic residue was detected in the investigated samples. Further efforts by all people involved in the production chain are required for ensuring suitable processing conditions as well as the harmlessness of milk and dairy products. Such practices may also contribute to consumer health and to the sustainability of the section within the investigated region.
\end{abstract}

Keywords: antibiotic, hygiene, microbiological standards, psychrotrophic.

\footnotetext{
${ }^{1}$ Instituto Capixaba de Pesquisa, Assistência Técnica e Extensão Rural (INCAPER), Alegre, ES

${ }^{2}$ Universidade Federal do Espírito Santo, UFES, Campus Alegre, ES

${ }^{3}$ Empresa de Pesquisa Agropecuária de Minas Gerais, EPAMIG, Viçosa-MG
} 


\section{INTRODUÇÃO}

A produção de leite no Brasil, em 2015, ficou em aproximadamente 36,2 bilhões de litros e de acordo com o Ministério da Agricultura, Pecuária e Abastecimento (MAPA) o leite e seus derivados exercem papel preponderante no fornecimento de alimentos e na geração de emprego para a população e está entre os seis produtos mais importantes da agropecuária brasileira. A implementação da Instrução Normativa ${ }^{\circ} 62$ pelo MAPA (BRASIL, 2011) impulsionou o setor lácteo, mas, em algumas regiões do país observam-se problemas relacionados às condições higiênico-sanitárias inadequadas durante os processos de obtenção, manipulação e armazenamento do leite cru refrigerado com comprometimento da sua qualidade e inocuidade (RAMOS et al., 2014; MENEZES et al., 2015; PINTO et al., 2015; ALMEIDA et al., 2016). Além disso, ainda são detectados resíduos de antibióticos em leite o que acarreta problemas à saúde dos consumidores (NERO et al., 2007; RODRIGUES et al., 2012). E no estado do Espírito Santo, a atividade leiteira exerce grande expressão socioeconômica e contribui para um dos principais setores do agronegócio na geração de renda e arrecadação tributária. Em 2015 o estado produziu em torno de 505,3 milhões de litros de leite, sendo que em torno de $(80 \%)$ da produção é fornecida por Agricultores Familiares ${ }^{3}$, (BRASIL, 2006) com produção média diária inferior a 100 litros. A cidade de Alegre, situada na região sul do estado possui a atividade leiteira como sustentabilidade econômica e social da maioria da população rural ativa, com um rebanho de 65.242 cabeças e a produção de leite foi da ordem de 16,2 milhões de litros com aproximadamente 1.368 propriedades cadastradas no Instituto de Defesa Agropecuária e Florestal do Espírito Santo (IDAF, 2013). No município, a produtividade anual, por vaca leiteira, fica em torno de 2.367 litros/ano e a atividade é desenvolvida em sua grande maioria por agricultores de base familiar, com hábitos culturais tradicionais que passam de pai para filho (IDAF, 2013). Por meio de visitas técnicas realizadas anteriormente em algumas propriedades rurais da região, constatou-se não conformidades nas características e no manejo empregado na produção e armazenamento do leite cru refrigerado. Essas inadequações foram em relação a adoção de hábitos higiênicos inadequados em relação aos utensílios e equipamentos utilizados na ordenha; a falta de realização de exames de saúde com o pessoal envolvido no processo; a não realização dos procedimentos de prédipping e pós-dipping além da falta de controle da mastite por meio da aplicação de testes específicos como o da caneca de fundo preto e o Califórnia Mastite Teste (CMT) (NETA, 2015).

E estas condições contribuem para a obtenção de um produto de baixa qualidade associado ao crescimento de micro-organismos prejudiciais à qualidade e inocuidade do leite. Mediante o exposto e a escassez de trabalhos realizados na região objetivou-se avaliar a qualidade do leite cru por meio da determinação de bactérias deteriorantes e patogênicas além da detecção de resíduos de antibióticos em leite cru produzido em propriedades de base familiar e armazenado em tanques de refrigeração situados no município de Alegre, ES.

\section{MATERIAL E MÉTODOS}

\section{Amostras de leite}

Foram avaliadas amostras de leite cru refrigerado armazenado em tanques coletivos instalados em quatro comunidades rurais do município de Alegre-ES as quais incluíam trinta e quatro (34) produtores cadastrados. Tais comunidades foram indicadas por técnicos do Instituto de Pesquisa, Assistência Técnica e Extensão Rural (INCAPER) e as quais caracterizam-se pois são compostas de mão de obra familiar na produção de leite e são relevantes na atividade leiteira para o município. As comunidades foram identificadas como: comunidade A (composta de 6 produtores rurais, correspondentes ao Tanque 1); comunidade $\mathrm{B}$ (12 produtores rurais correspondentes ao Tanque 2); comunidade C (5 produtores rurais correspondentes ao Tanque 3); comunidade $\mathrm{D}$ (11 produtores rurais correspondentes ao Tanque 4).

Foram coletadas duas amostras de leite em cada tanque, com volume de $500 \mathrm{~mL}$ cada, durante o período da seca, em frascos esterilizados os quais foram acondicionados e transportados em caixas isotérmicas com gelo reciclável. As análises foram realizadas no Laboratório de Microbiologia e Química de Alimentos

${ }^{1}$ Agricultores Familiares são os agricultores inseridos no Programa Nacional de Fortalecimento da Agricultura Familiar, segundo a Lei $\mathrm{n}^{\circ} 11.326$, de 24 de julho de 2006 (BRASIL, 2006). 
do Instituto Federal de Educação, Ciência e Tecnologia do Espírito Santo (IFES), Campus de Alegre, ES.

\section{Análises microbiológicas e detecção de resíduos de antibióticos}

As amostras de leite cru foram submetidas à contagem de bactérias mesófilas (BM); bactérias psicrotróficas (BP) e as metodologias empregadas foram aquelas descritas pela APHA (2001). Empregou-se Placa Petrifilm ${ }^{\mathrm{TM}}$ de acordo com procedimento descrito pelo fabricante para contagem Staphylococcus spp (Staphy); coliformes totais (CT) e de Escherichia coli (EC).

A detecção de resíduos de antibióticos foi feita em triplicata por meio do kit BetaStar ${ }^{\circledR} 250$, com metodologia de acordo com as instruções do fabricante. Amostras de leite foram transferidas para os tubos contendo receptores â-lactâmicos, procedeu-se agitação e incubação por $47,5^{\circ} \mathrm{C}$ em estufa bacteriológica. Tratase de uma técnica imunológica para detecção de resíduos de antibióticos do grupo ß-lactâmicos (penicilina, ampicilina, amoxicilina, cloxacilina e cefapirina) usados com frequência no tratamento de mastite bovina. Utilizase um receptor específico de â-lactâmico®e uma proteína ligada a partículas de ouro.

Os dados foram analisados por meio do emprego de estatística descritiva utilizando-se o programa SAEG, versão 9.1 (SAEG, 2007). Os resultados das análises microbiológicas e da pesquisa de resíduos de antibióticos foram comparados com os padrões legais preconizados.

\section{RESULTADOS E DISCUSSÃO}

Amostras de leite cru refrigerado coletadas nos tanques 1 e 3 apresentaram-se de acordo com os padrões legais para a contagem de bactérias mesófilas (BM) (Tabela 1). Ao contrário das amostras coletadas nos tanques 2 e 4 que apresentaram contagens superiores ao limite de 6,0x10 UFC. $^{-1} L^{-1}$ estabelecido peloMAPA(BRASIL, 2011).
As altas contagens de bactérias mesófilas encontradas nessas amostras de leite são provenientes de falhas observadas nos procedimentos empregados na higienização; das condições inapropriadas de produção e nos locais dos tanques de armazenamento. Além disso, todos os tanques de refrigeração eram do tipo coletivo e neste caso, verificou-se maior risco de contaminação considerando a mistura de leite proveniente de diversas propriedades rurais.

BOZO et al. (2013) avaliaram a qualidade do leite cru refrigerado de cinco propriedades leiteiras no estado do Paraná e os valores médios de Contagem Bacteriana

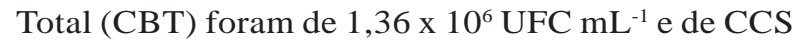
de $1,87 \times 10^{6} \mathrm{CS} \mathrm{mL}^{-1}$. Eles verificaram que após a implantação de boas práticas de ordenha e adoção de recomendações quanto ao tratamento de mastite e à manutenção e higienização dos equipamentos de ordenha houve uma redução média de $93,4 \%$ na CBT e $74,3 \%$ na CCS e ainda resultaram em um aumento da renda mensal.

SOBRINHO et al. (2012) analisaram a qualidade bacteriológica de amostras de leite cru oriundas de seis propriedades rurais que fabricavam queijos artesanais do Serro, em Minas Gerais os quais são fabricados com leite cru. Os autores constataram valores de contagem bacteriana total (CBT) em torno de 1,87 a 7,88 log de UFC $\mathrm{mL}^{-1}$. E os valores encontrados de contagem de células somáticas (CCS) foram de 10.000 a 1.390 .000 células $/ \mathrm{mL}$ e os valores não diferiram significativamente entre as estações do ano, mas sim entre as diferentes propriedades rurais. Resultados semelhantes a este trabalho foram constatados em outras regiões. HOOGERHEIDE e MATTIODA (2012) ao avaliarem a qualidade do leite cru refrigerado na bacia leiteira do Estado do Paraná, verificaram que $72,73 \%$ das amostras estavam acima do limite estabelecido para CBT e que a baixa qualidade do leite foi devida

Tabela 1 - Valores médios da contagem de bactérias mesófilas (BM), bactérias psicrotróficas (BP) e relação BP/BM em amostras de leite cru refrigerado

\begin{tabular}{cccc}
\hline Tanques & Bactérias mesófilas(BM) $\left(\mathrm{UFC} . \mathrm{mL}^{-1}\right)$ & Bactérias psicrotróficas (BP)(UFC.mL $\left.{ }^{-1}\right)$ & Relação \\
\hline 1 & $5,7 \times 10^{5}$ & $3,6 \times 10^{5}$ & 63,0 \\
2 & $2,6 \times 10^{6 *}$ & $1,5 \times 10^{6}$ & 58,1 \\
3 & $1,6 \times 10^{5}$ & $2,2 \times 10^{5}$ & 140,5 \\
4 & $2,5 \times 10^{6 *}$ & $3,6 \times 10^{5}$ & 14,5 \\
\hline
\end{tabular}

* Não conformidade com a Instrução Normativa $N^{\circ} 62$ (BRASIL, 2011). 
também à falta de procedimentos corretos de higiene na ordenha.

As contagens médias de bactérias psicrotróficas encontram-se na Tabela 1 . Os valores variaram de $2,2 \times 10^{5}$ UFC.mL ${ }^{-1}$ a $1,5 \times 10^{6}$ UFC.mL ${ }^{-1}$. Em todas as amostras de leite coletadas nos tanques verificaram-se contagens de bactérias psicrotróficas superiores a $10 \%$ da contagem de bactérias mesófilas, o que reforça a necessidade de revisão nos procedimentos de higiene adotados na região com relação à produção, transporte e nos tanques de armazenamento do leite. Embora a refrigeração seja uma prática aliada à qualidade do leite, e requerida pela legislação, a ausência de práticas que reduzam a contaminação nos processos iniciais de obtenção do leite influenciam diretamente na proliferação de bactérias psicrotróficas.

BERSOT et al. (2010) encontraram resultados semelhantes a este trabalho ao constatarem valores de bactérias psicrotróficas superiores a $10^{6} \mathrm{UFC} . \mathrm{mL}$ ${ }^{1}$ em amostras de leite coletadas em sete de treze das propriedades rurais $(53,8 \%)$ pertencentes à região de Pelotina, PR. Em estudos realizados por NÖRNBERG et al. (2009) também foram relatadas altas contagens de bactérias psicrotróficas em amostras de leite cru refrigerado da ordem de $10^{6}$ UFC. $\mathrm{mL}^{-1}$. De acordo com COUSIN, 1982, embora não exista padrão para esse grupo microbiano, os valores não devem ser superiores a $10 \%$ da contagem de bactérias mesófilas considerando que muitas espécies pertencentes a esse grupo de microorganismos apresentam alto potencial deteriorante, e assim podem comprometer a inocuidade do produto. Bactérias psicrotróficas produzem enzimas proteases termorresistentes, as quais hidrolisam todos os tipos de caseína (BAGLINIÈRE et al., 2012) e este fato está associado à ocorrência de problemas tecnológicos na indústria tais como a gelificação e a sedimentação do leite Ultra High Temperature (UHT); sabores indesejáveis em produtos derivados e redução do rendimento na elaboração de queijos (SØRHAUG;STEPANIAK, 1997; VESCONSI et al., 2012).

Os dados apresentados na Tabela 2 mostram que em $100 \%$ das amostras de leite cru coletadas nos tanques de refrigeração constatou-se a presença de Staphylococcus spp., com contagens médias que variaram de $3,3 \times 10^{4}$ UFC.mL-1 a 9, $1 \times 10^{5}$ UFC.mL ${ }^{-1}$.

Não há padrão estabelecido para esse microorganismo patogênico em leite cru e sabe-se que sua
Tabela 2 - Valores médios da contagem de Staphylococcus spp. em amostras de leite cru refrigerado

\begin{tabular}{|c|c|}
\hline Tanque & Staphylococcus spp. (Staphy) (UFC. $\left.\mathrm{mL}^{-1}\right)$ \\
\hline 1 & $4,8 \times 10^{4}$ \\
\hline 2 & $9,1 \times 10^{5}$ \\
\hline 3 & $3,3 \times 10^{4}$ \\
\hline 4 & $1,8 \times 10^{5}$ \\
\hline
\end{tabular}

presença está associada a falhas nos procedimentos de higienização. E neste trabalho constatou-se inadequações em relação à higienização de utensílios e equipamentos de ordenha, manipulação, higienização inadequada das mãos dos ordenhadores, falhas nos procedimentos de armazenamento do leite nos tanques além da presença de mastite clínica e subclínica. Resultados semelhantes foram encontrados por ALMEIDA et al. (2016) ao caracterizarem o manejo produtivo geral adotado em unidades agrícolas familiares em municípios no norte de Minas Gerais e Staphylococcus sp. foi isolado em 9,05\% (36) do total de amostras analisadas e coletadas principalmente no período chuvoso. Os autores verificaram que a maior incidência desse micro-organismo neste período está relacionada, provavelmente, às deficiências no manejo adotado durante a ordenha, como falhas na higienização dos tetos além de quadros de mastite nos rebanhos envolvidos. Resultados semelhantes foram encontrados por LAMAITA et al. (2005) ao constatarem Staphylococcus sp. em $100 \%$ das amostras de leite cru refrigerado a $4{ }^{\circ} \mathrm{C}$, estocado por 48 horas em tanques de refrigeração instalados propriedades rurais da área metropolitana de Belo Horizonte em concentrações entre $1,0 \times 10^{5}$ a $2,5 \times 10^{7}$ UFC. $\mathrm{mL}^{-1}$ além de enterotoxinas estafilocócicas (SE) e toxina da síndrome do choque tóxico (TSST-1). SANTANA et al. (2006) detectaram estafilococos coagulase positiva(ECP) em 101 amostras de leite cru das regiões de Pelotas e Londrina,PR, sendo que $19(18,8 \%)$ apresentaram contagens acima de $10^{5}$ UFC. $\mathrm{mL}^{-1}$.

Os dados apresentados na Tabela 3 indicam que em todas as amostras analisadas foram detectadas bactérias do grupo coliformes totais, com contagem média

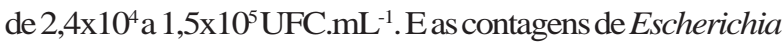
coli nas amostras coletadas nos Tanques 2, 3 e 4 variaram de 5,0x10² UFC.mL-1 a 1,7x10 UFC. $\mathrm{mL}^{-1}$.

Os resultados desse estudo estão de acordo com os encontrados por MENEZES et al. (2015) que, ao analisarem amostras de leite cru na região Norte de 
Tabela 3 - Valores médios da contagem de coliformes totais e de Escherichia coli em amostras de leite cru refrigerado

\begin{tabular}{ccc}
\hline Tanque & Coliformes totais $(\mathrm{CT})\left(\mathrm{UFC}_{\mathrm{mL}}{ }^{-1}\right)$ & Escherichia coli $(\mathrm{Ec})\left(\mathrm{UFC} . \mathrm{mL}^{-1}\right)$ \\
\hline 1 & $2,4 \times 10^{4}$ & Não detectado \\
2 & $7,9 \times 10^{4}$ & $5,0 \times 10^{2}$ \\
3 & $8,3 \times 10^{4}$ & $4,7 \times 10^{3}$ \\
4 & $1,5 \times 10^{5}$ & $1,7 \times 10^{5}$ \\
\hline
\end{tabular}

Minas Gerais constataram alto grau de contaminação do leite com esses grupos microbianos. Essas contaminações foram também relacionadas com inadequações nas práticas higiênicas empregadas para higienização de equipamentos de ordenha.

Neste estudo, os resultados das análises microbiológicas os quais mostram a baixa qualidade do leite cru no município de Alegre, vêm a corroborar com os encontrados por NETA et al., 2015, em relação às condições e práticas de produção de leite empregadas por trinta e quatro proprietários rurais, bem como as condições de armazenamento e estruturas dos locais de instalação de quatro tanques de refrigeração coletivos nesta mesma região. Os autores concluíram que (21 $\%)$ dos produtores realizavam o pré dipping e (6\%) realizavam o pós-dipping e apenas $25 \%$ dos produtores realizavam o teste da caneca de fundo preto. Todos os equipamentos eram higienizados após a ordenha, mas apenas $(5 \%)$ utilizavam sanitizantes nos equipamentos e ( $94 \%$ ) das propriedades usavam água não tratada. Nenhuma instalação possuía proteção contra entrada de insetos, roedores, contaminantes ambientais e eram mal dimensionadas, não permitiam a aplicação de medidas sanitárias adequadas e essas características de produção empregadas por esses produtores rurais contribuíram para a obtenção de leite com baixa qualidade na região constatada neste estudo.

Resultados semelhantes a este trabalho foram verificados por RAMOS et al. (2013) ao avaliarem as características de manejo utilizadas em trinta propriedades rurais do município de São Mateus-ES, situado na região Norte do Estado. Os autores constataram que somente (40\%) dos ordenhadores lavavam as mãos e antebraços antes da ordenha e (13\%) usavam soluções antissépticas; apenas $4 \%$ dos ordenhadores realizavam os exames periódicos de saúde, nenhuma das propriedades empregava os procedimentos de pré-dipping e pósdipping, e em (100\%) das vacas não eram realizados o CMT.
Além disso, RAMOS et al. (2014), ao avaliarem vinte e oito propriedades localizadas em outra região do município de São Mateus, constataram também alto percentual de inadequações nos requisitos de estrutura física e limpeza tanto dos estábulos quanto nos utensílios utilizados no processo de ordenha. Em $(100 \%)$ das propriedades rurais não realizavam o procedimento de pré-dipping e pós-dipping. O alto grau de não conformidades constatado em relação às características de produção empregadas nessas propriedades rurais compromete a qualidade e a inocuidade do leite cru e dos produtos lácteos da região norte do Estado.

No presente trabalho, não foram detectados resíduos de antibióticos nas amostras de leite cru coletadas nos quatro tanques coletivos no município de Alegre, o que pode ser associado, provavelmente, ao cumprimento dos produtores rurais do período de carência recomendado pelo fabricante.

\section{CONCLUSÕES}

A baixa qualidade microbiológica do leite cru refrigerado produzido na região de Alegre, ES verificada pelo alto grau de contaminação do leite por bactérias mesófilas, psicrotróficas, Staphylococcus spp. e bactérias do grupo coliformes é indicativa da necessidade de intervenções no processo de obtenção e armazenamento do produto. Os resultados do presente estudo reforçam a necessidade de adoção e implementação das Boas Práticas Agropecuárias por parte dos produtores rurais e demais setores envolvidos na cadeia produtiva, a fim de garantir a qualidade e inocuidade do leite e derivados, além de contribuir para a saúde dos consumidores e a sustentabilidade do setor na região.

\section{LITERATURA CITADA}

APHA. Compendium of Methods for the Microbiological Examination of Foods. 4nd ed. American Public Health Association, Washington, DC, 2001. 
ALMEIDA, A.C.; SANTOS, C.A.; MENEZES, I.R.; TEIXEIRA, L.M.; COSTA, J.P.R.; SOUZA, R.M. Perfil sanitário de unidades agrícolas familiares produtoras de leite cru e adequação à legislação vigente. Ciência Animal Brasileira, Goiânia, v.17, n.3, p. 303-315, 2016.

BAGLINIÈRE, F. et al. Quantitative and qualitative variability of the caseinolytic potential of different strains of Pseudomonas fluorescens: Implications for the stability of casein micelles of UHT milks during their storage. Food

Chemistry, v. 135, n. 4, p. 2593-2603, 2012.

BERSOT, L. S. et al. Raw milk trade: profile of the consumers and microbiological and

physicochemical characterization of the product in Palotina-PR region. Revista do Instituto de Laticínios Cândido Tostes, Juiz de Fora, v. 65 , n. 373, p. 3-8, 2010.

BOZO, G. A.; ALEGRO, L. C. A.; SILVA, L. C.; SANTANA, E. H. W.; OKANO, W.; SILVA, L. C. C. Adequação da contagem de células somáticas e da contagem bacteriana total em leite cru refrigerado aos parâmetros da legislação. Arquivo

Brasileiro de Medicina Veterinária e Zootecnia, v. 65, n. 2, p. 589-594, 2013.

BRASIL. Ministério da Agricultura, Pecuária e Abastecimento. Instrução Normativa ${ }^{\circ}$ 62, de 29 de dezembro de 2011. Aprova o Regulamento Técnico de Produção, Identidade e Qualidade do Leite tipo A, o Regulamento Técnico de Identidade e Qualidade de Leite Cru Refrigerado, o Regulamento Técnico de Identidade e Qualidade de Leite Pasteurizado e o Regulamento Técnico da Coleta de Leite Cru Refrigerado e seu Transporte a Granel, em conformidade com os Anexos desta Instrução Normativa. Diário Oficial da República Federativa do Brasil, Brasília, DF, 31 de dezembro de 2011. Seção 1, p. 6.

BRASIL, Lei 11.326, 24 de julho de 2006. Estabelece as diretrizes para a formulação da Política Nacional da Agricultura Familiar e Empreendimentos Familiares Rurais. Diário Oficial da União. Brasília, DF, 2006.

COUSIN, M. A. Presence and activity of Psychrotrophic bacteria in South East Queensland dairy produts. The Australian Journal of Dairy Techonology. v. 37, p. 147, 1982.
HOOGERHEIDE, S. L.; MATTIODA, F. Qualidade bacteriológica do leite cru refrigerado em propriedades rurais do estado do Paraná.

Revista do Instituto de Laticínios

Cândido Tostes, v. 67, n. 385, 2012.

INSTITUTO DE DEFESAAGROPECUÁRIAE FLORESTAL DO ESPÍRITO SANTO - (IDAF). Relatório Anual de Bovinos Cadastrados no Município de AlegreES/2012. Alegre, ES, 2013.

LAMAITA, H. C. Contagem de Staphylococcus sp e detecção de enterotoxinas estafilocócicas e toxina da síndrome do choque tóxico em amostras de leite cru refrigerado. Arquivos Brasileiros de Méd. Veterinária e Zootecnia, v. 57, n. 5, p. 702-709, 2005.

MENEZES, I. R.; ALMEIDA, A.C.; MORÃO, R.P.; REIS, S.V.R.; SANTOS, C.A.; LOPES, I.L.N. Qualidade microbiológica do leite cru produzido no Norte de Minas Gerais. Revista Brasileira de Ciência e Veterinária, v. 22, n. 1, p. 5863, 2015.

NERO, L.A.; MATTOS, M.R.; BELOTI, V.; BARROS, M.A.F.; FRANCO, B.D.G.M. Resíduos de antibiotic em leite cru de quatro regiões leiteiras no Brasil. Ciência e Tecnologia de Alimentos, Campinas, 27(2):391-393, 2007.

NETA, F.C.N.; JUNQUEIRA, M.S.; CARNEIRO, J.C.S.; RAMOS, M.P.P.; ABDALLAH,F.R.; FRACALOSSI, C.P. Condições de produção de leite em propriedades familiares localizadas no município de Alegre - ES, Brasil. Revista do Instituto de Laticínios Cândido Tostes, [S.1.], v. 70, n. 3, p. 117-131, dez. 2015.

NÖRNBERG, M. F. B. L.; TONDO, E. C.; BRANDELLI, A. Bactérias psicrotróficas e atividade proteolítica no leite cru refrigerado. Acta Scientia Veterinaria, v. 37, n. 2, p.157-163, 2009.

PINTO, C.L.O.; MACHADO, S.G.; MARTINS, M.L.; VANETTI, M.C.D. Identificação de bactérias psicrotróficas proteolíticas isoladas de leite cru refrigerado e caracterização do seu potencial deteriorador. Revista do Instituto de Laticínios Cândido Tostes, v. 70, n. 2, p. 105-116, 2015. 
RAMOS, M. P. P. et al. Qualidade microbiológica e fatores que influenciam a produção de leite obtido de propriedades familiares no norte do Estado do Espírito Santo. Revista Brasileira de Agropecuária Sustentável, v.4, n. 1, p. 1-15, 2014.

RAMOS, M. P. P. et al. Milk production practices on family farms located north of the State of Espírito Santo, Brazil. Journal of Agricultural Science and Technology, v. 3, n. 11, p. 920-926, 2013.

RODRIGUES, M.X.; DALL'AGNOL. L.; BITTENCOURT, J.V.M. Levantamento da Ocorrência de Resíduos de Antibióticos em Leite Cru Produzido na Região dos Campos Gerais, Paraná. Unopar Científica. Ciências Biológicas e da Saúde, v.14, n.4, p. 237-40,2012.

SANTANA, E. H. W.; BELOTI, V.; OLIVEIRA, T. C. R. M.; MORAES, L. B.; TAMANINI, R.; SILVA, W. P. Estafilococos: morfologia das colônias, produção de coagulase e enterotoxina a, em amostras isoladas de leite cru refrigerado, Semina: Ciências Agrárias, Londrina. v. 27, n. 4, p. 639-646, 2006.
SAEG - Sistema para Análises Estatísticas, Versão 9.1: Fundação Arthur Bernardes - Universidade Federal de Viçosa, Viçosa, MG, 2007.

SOBRINHO, P. S. C.; FARIA, C. A. M.; PINHEIRO, J. S.; ALMEIDA, H. G.; PIRES, C. V.; SANTOS, A. S. Bacteriological quality of raw milk used for production of a brazilian farmstead raw milk cheese. Foodborne Pathogens and Disease, v. 9, n. 2, Feb. 2012.

SØRHAUG, T.; STEPANIAK, L. Psychrotrophs and their enzymes in milk and dairy products: Quality aspects. Trends in Food Science \&Technology, v. 8, n. 2, p. 35-41, 1997.

VESCONSI, C.N.; VALDUGA, A.T.; CICHOSKI, A.J. Sedimentação do leite UHT integral, semidesnatado e desnatado durante armazenamento. Ciência Rural, v. 42, n. 4, p.730-736, 2012.

Recebido para publicação em 15/04/2016 e aprovado em 10/09/2016 